\title{
The fts $A$ Gene Product: a Possible Connection between DNA Replication and Septation in Escherichia coli
}

\author{
By ANTONIO TORMO, * CONCEPCIÓN FERNÁNDEZ-CABRERA AND \\ MIGUEL VICENTE \\ Instituto de Biología Celular, Consejo Superior de Investigaciones Cientificas, Velázquez 144, \\ 28006 Madrid, Spain
}

(Received 15 March 1984; revised 4 July 1984)

\begin{abstract}
The study of Escherichia coli strain D-2, which harbours the $f t s A 2(\mathrm{ts})$ allele, has shown that temperature-induced filaments of this strain can divide, at $30^{\circ} \mathrm{C}$, in the absence of DNA replication and translation. Strain D-2 is thermosensitive during a period coincident with that in which the termination protein should be synthesized and exert its action. The $f t s A$ gene product, which participates in the structure of the septum, needs for its synthesis a short period of DNA replication. The FtsA protein could be involved in a mechanism that coordinates chromosome replication and cell division by a pathway different from and independent of the SOS-induced response.
\end{abstract}

\section{INTRODUCTION}

Division in Escherichia coli is a discontinuous event but, during balanced growth, it is well coordinated with several growth processes such as duplication of the length, mass, volume and DNA content of the cell. These processes as such are largely continuous during the lifespan of a cell, except for initiation and termination of chromosome replication. The dependence of cell division on DNA replication has been described (Clark, 1968; Helmstetter \& Pierucci, 1968). Inhibition of the rounds of chromosome replication is followed by a stop in cell division. Jones \& Donachie (1973) postulated the existence of effector(s) required for cell division that would be synthesized at the end of a round of replication, their synthesis, in turn, requiring active replication and transcription. This effector(s) was named termination protein(s) and is supposed to coordinate chromosome replication and cell division under normal growth conditions.

Mutants affected in this postulated termination protein have not been described up to now and, also, a molecular species having the properties of a termination protein has not been found (Lutkenhaus et al., 1979). The results of Donachie et al. (1979) and Tormo et al. (1980) have shown that the period of action and synthesis of the $f t s A$ gene product occurs during the late stages of the E. coli cell cycle. Moreover, the synthesis and/or action of the FtsA protein needs a short pulse of DNA synthesis. In $f t s A$ mutants a thermal shock during the period of synthesis and action of the termination protein prevents cell division even if all other requirements for division are fulfilled (Donachie et al., 1979; Tormo et al., 1980). These results suggest that the role of FtsA is in some respects similar to that of a termination protein (Tormo et al., 1980). Other results (Tormo \& Vicente, 1984; A. Tormo, M. Vicente \& M. A. de Pedro, unpublished results) have shown that FtsA is located in the inner membrane, having a structural role in the formation of the division septa.

In this work the physiology of E. coli strains D-2 and D-3 containing different $f t s A$ alleles has been studied. The results obtained support those previously described for $f t s A$ mutants (Donachie et al., 1979; Tormo et al., 1980) and suggest that the role of FtsA is similar to that of a termination protein. Our results corroborate the need for DNA synthesis for the recovery of septation in filaments of $f t s A 3$, but they show that this is a requirement for the synthesis of the $f t s A$ gene product and not for its action. 


\section{METHODS}

Bacterial strains. The $E$. coli $\mathrm{K} 12$ strains used in this work, D-2 and D-3, are derivatives of OV-2 (Donachie et al., 1976): $\mathrm{F}^{-}$leu ilv his thy $A($ deo $)$ ara (Am) lacl25(Am) galE trp(Am) tsx (Am) tyrT(supF A81ts). D-2: as OV-2, leu $u^{+}$tsA2(ts) (Tormo \& Vicente, 1984). D-3: as OV-2, leu ${ }^{+}$ftsA3(ts) (Tormo et al., 1980).

$M e d i a$ and growth conditions. Cells were grown in LB medium supplemented with $20 \mu \mathrm{g}$ thymine $\mathrm{ml}^{-1}$. Minimal medium was M9 (Clowes \& Hayes, 1968) with glucose as a carbon source $\left(4 \mathrm{mg} \mathrm{ml}^{-1}\right)$; the auxotrophic requirements of the strain, adenine, uracil and cytosine $\left(20 \mu \mathrm{g} \mathrm{ml}^{-1}\right.$ each) and Casamino acids $\left(5 \mathrm{mg} \mathrm{ml}^{-1}\right)$ were also added.

Cells were grown at the permissive temperature $\left(30^{\circ} \mathrm{C}\right)$ in liquid media in a shaking water-bath so that balanced growth was maintained during several doublings (no less than four) before the beginning of the experiment. Procedures for cell parameter measurements, photomicrography of nucleoids and chromosome alignment have been described previously (Tormo et al., 1980).

Inhibitors. DNA replication was inhibited by nalidixic acid $\left(80 \mu \mathrm{g} \mathrm{ml}^{-1}\right.$, final concn) or by hydroxyurea (15 mg ml-1, final concn). Transcription was inhibited with rifampicin $\left(500 \mu \mathrm{g} \mathrm{ml}^{-1}\right.$, final concn). Protein synthesis was inhibited with chloramphenicol $\left(200 \mu \mathrm{g} \mathrm{ml}^{-1}\right.$, final concn).

\section{RESULTS AND DISCUSSION}

\section{Physiological characterization of strain D-2 ( $f$ ts A2)}

Strain D-2 contains a temperature-sensitive division mutation, shown by complementation analysis to be an allele of $f t s A$ and termed $f t s A 2(t s)$ (Tormo \& Vicente, 1984). The kinetics of increase in $\mathrm{OD}_{450}$, particle number and viable counts at $30^{\circ} \mathrm{C}$ occurred at a rate similar to that found with the parent strain OV-2 (Fig. 1). At $42^{\circ} \mathrm{C}$ (restrictive temperature) $\mathrm{OD}_{450}$ increased at a higher rate (as expected in a temperature shift-up) but particle number and viable counts remained constant, showing that no cell division occurred (Fig. 1). DNA synthesis and nucleoid segregation suffered no detectable alterations at $42^{\circ} \mathrm{C}$ as filaments of strain D-2 had several nucleoids uniformly distributed throughout their length (results not shown). The fact that no cell division occurred upon transfer to the restrictive temperature corroborated the need for an active FtsA protein until cell separation, as has already been suggested (Tormo et al., 1980).

As expected from the behaviour of other $f t s A$ alleles (Donachie et al., 1979; Tormo et al., 1980) it was found that strain D-2 is thermosensitive during the last stages of the division cycle and that cells in which all the requirements for division are present, except expression of the $f t s A$ gene, fail to divide under restrictive conditions (results not shown). The behaviour of strain D-2 is therefore compatible with that of a strain with a thermosensitive termination protein.

\section{Recovery of division at $30^{\circ} \mathrm{C}$ in temperature-induced filaments of strain D-3 ( $\mathrm{ftsA3}$ ): requirement for replication and transcription}

Filaments of strain D-3 ( $f t s A 3$ ), a temperature-irreversible $f t s A$ mutant, cannot divide upon return to $30^{\circ} \mathrm{C}$ if replication is inhibited by nalidixic acid or if translation is blocked by chloramphenicol when the culture is returned to permissive conditions (Tormo et al., 1980). But if a short pulse of replication and translation is allowed after the return of strain D-3 filaments to $30^{\circ} \mathrm{C}$, they are then able to divide (Tormo et al., 1980). The fact that translation is needed for the recovery of division in strain D-3 is easily explained if the inactivation of the $f t s A 3$ gene product were irreversible. The need for DNA replication is harder to understand. Among various possibilities three seem plausible to explain the observed behaviour. First, the inhibitor, nalidixic acid, could inhibit both replication and cell division. Second, inhibition of DNA replication by nalidixic acid treatment can induce the SOS response (Little \& Mount, 1982; Witkin, 1976), the inhibition of cell division being one of its side effects. Third, the fts $A$ gene product may need for its synthesis and/or action a short period of replication. An experiment was designed to test the first possibility. Temperature-induced filaments of strain D-3 were transferred to permissive conditions and replication was inhibited at the moment of transfer, or 20 min later, by hydroxyurea (an inhibitor of replication not related in its molecular structure or action to nalidixic acid). The results (Fig. 2) showed that cell division was inhibited if replication was blocked by hydroxyurea at the time of transfer but not if it was blocked 20 min later. Therefore, we can reasonably rule out the first possibility, a side effect of nalidixic acid on cell 

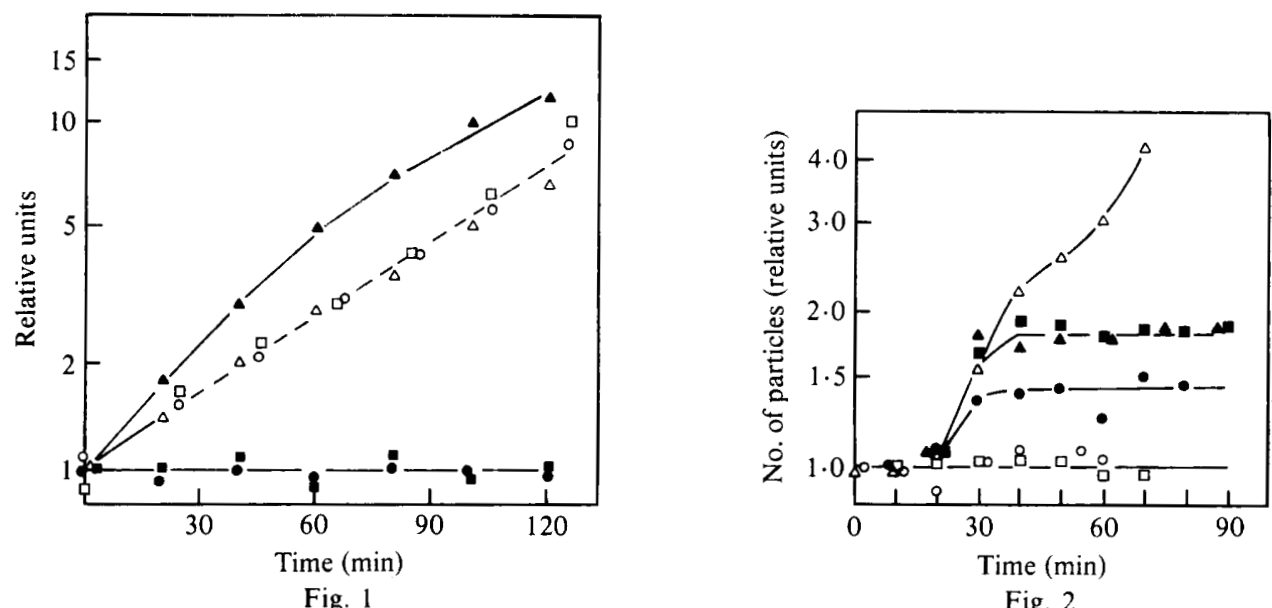

Fig. 1. Kinetics of growth of strain D-2 at 30 and $42{ }^{\circ} \mathrm{C}$. A culture growing at $30^{\circ} \mathrm{C}$ in LB medium supplemented with thymine was divided in two. One half was kept at $30^{\circ} \mathrm{C}$ (open symbols) and the other was shifted to $42^{\circ} \mathrm{C}$ at time 0 (filled symbols). Increases in $\operatorname{OD}_{450}(\triangle, \Delta)$, cell number $(O, O)$ and viable counts $(\square, \square)$ were measured at the times indicated. Initial values were: $2.6 \times 10^{7}$ particles $\mathrm{ml}^{-1}, 1.5 \times 10^{7}$ viable cells $\mathrm{ml}^{-1}$ and $0.1 \mathrm{OD}_{450}$ units.

Fig. 2. Recovery of division in temperature-induced filaments of strain D-3. A culture growing exponentially at $30^{\circ} \mathrm{C}$ in $\mathrm{LB}$ medium supplemented with thymine was shifted to $42^{\circ} \mathrm{C}$. After $30 \mathrm{~min}$ at this temperature, the culture was divided into several parts that were shifted back to $30^{\circ} \mathrm{C}$ at time 0 . Hydroxyurea was added at $0 \mathrm{~min}(\square)$ or at $20 \mathrm{~min}(\square)$; rifampicin was added at $0 \mathrm{~min}(\bigcirc)$, at $10 \mathrm{~min}$ (C) or at $20 \mathrm{~min}(\Delta)$; one part was transferred to $30^{\circ} \mathrm{C}$ without any inhibitor as a control $(\triangle)$. The initial value was $3.5 \times 10^{7}$ particles $\mathrm{ml}^{-1}$.

division, as it seems unlikely that hydroxyurea would cause the same side effects as nalidixic acid. That transcription is required to allow cell division upon return to permissive conditions is in accordance with our interpretation that the $f t s A 3$ gene product is irreversibly inactivated at $42{ }^{\circ} \mathrm{C}$ (Tormo \& Vicente, 1984), as was also found when rifampicin was used to inhibit transcription. Filaments of strain D-3 therefore needed translation and transcription to resume division.

Almost any inhibition of DNA replication induces the SOS response (Little \& Mount, 1982; Witkin, 1976), one effect of which is a transient inhibition of cell division. Although nalidixic acid has been reported to induce the SOS response (Little \& Mount, 1982), it is not yet known whether every block in DNA replication inhibits cell division as a consequence of the SOS response or through some other mechanism that could coordinate replication and cell division. The SOS response induced by different treatments has different pleiotropic effects (Barbe et al., 1983). Moreover, thymine starvation, reported to induce the SOS response (Little \& Mount, 1982), does not inhibit cell division immediately, permitting a high residual division. It was, therefore, an open question whether the absence of division of temperature-induced filaments of strain D-3 at $30^{\circ} \mathrm{C}$ when DNA synthesis was inhibited (Tormo et al., 1980 and Fig. 2) was due to a possible SOS response or whether replication was needed for the synthesis and/or action of FtsA. The first explanation did not seem very plausible because filaments of strain D-3 could not divide if replication was inhibited at the time the cells were transferred to the permissive temperature but they readily divided if DNA synthesis was inhibited a few minutes later (Tormo et al., 1980 and Fig. 2). It is difficult to understand why the SOS response, if it was induced by nalidixic acid, could inhibit cell division when it was added at the time of transfer of the filaments to purmissive conditions but not when added $5 \mathrm{~min}$ later. The possibility that FtsA needs a short pulse of replication for its synthesis and/or action seems, from these results, more plausible. 


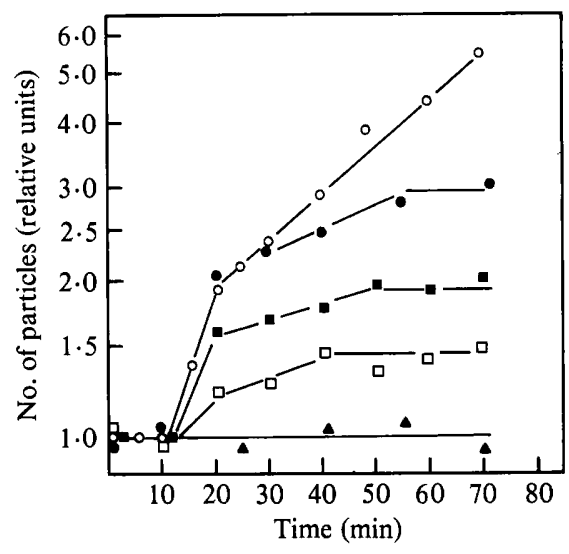

Fig. 3

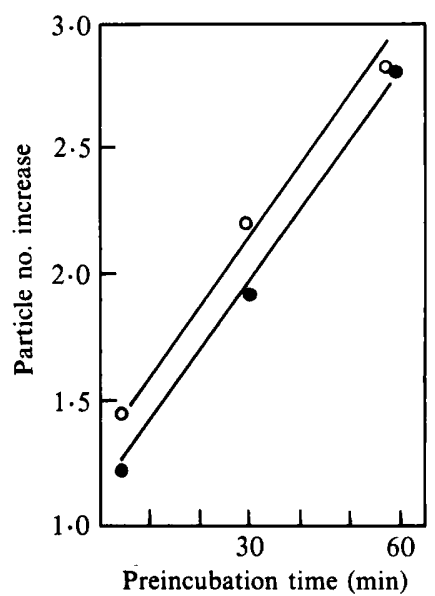

Fig. 4

Fig. 3. Recovery of division in temperature-induced filaments of strain D-2[fts $A 2(\mathrm{ts})$, thermoreversible]. A culture growing at $30^{\circ} \mathrm{C}$ in $\mathrm{LB}$ medium supplemented with thymine was shifted to $42^{\circ} \mathrm{C}$. After $30 \mathrm{~min}$ at this temperature the culture was divided into several parts that were shifted back to $30^{\circ} \mathrm{C}$ at time 0 . Hydroxyurea (O), nalidixic acid $(\square)$ or chloramphenicol $(\square)$ were added at time 0 to different parts; one part without inhibitor was the control (O); a fifth part was kept at $42^{\circ} \mathrm{C}(\boldsymbol{\Lambda})$. The initial value was $2.3 \times 10^{7}$ particles $\mathrm{ml}^{-1}$.

Fig. 4. Particle number increase in temperature-induced filaments of strain $D-2$ in the absence of replication. A culture of D-2 growing in LB medium supplemented with thymine was divided into several parts that were shifted to $42^{\circ} \mathrm{C}$ and kept at this temperature for 5,30 or $60 \mathrm{~min}$. After these periods of preincubation at the restrictive temperature the different portions were divided in two and returned to $30^{\circ} \mathrm{C}$ in the presence or absence of nalidixic acid $\left(80 \mu \mathrm{g} \mathrm{ml}^{-1}\right.$ final concentration). The kinetics of increase in cell number was followed. The residual increase in cell number in the presence of nalidixic acid (O) and the increase in cell number after $25 \mathrm{~min}$ at $30^{\circ} \mathrm{C}$ in the absence of the inhibitor (O) were plotted versus the time of preincubation at $42^{\circ} \mathrm{C}$. The initial value was $2.5 \times 10^{7}$ particles $\mathrm{ml}^{-1}$.

\section{Recovery of division at $30^{\circ} \mathrm{C}$ in temperature-induced filaments of strain $\mathrm{D}-2$ is independent of translation and replication}

Strain D-2 contains an $f t s A 2$ allele in which the gene product has been described as reversibly thermosensitive (Tormo \& Vicente, 1984). Temperature-induced filaments of this strain are therefore able to divide upon return to permissive conditions, even in the absence of protein synthesis. To find out whether the first division that occurs upon transfer of these filaments to permissive conditions was dependent on replication, the kinetics of cell division in temperatureinduced filaments of strain D-2 in the presence of different inhibitors was measured. The results (Fig. 3) indicate that division of strain D-2 filaments, under permissive conditions, could occur not only in the absence of translation, as already described (Tormo \& Vicente, 1984), but also in the absence of replication (i.e. in the presence of nalidixic acid or hydroxyurea). As the ftsA2 gene product is thermoreversible the rate of cell division of filaments returned to $30^{\circ} \mathrm{C}$ should increase as a function of the time spent at $42^{\circ} \mathrm{C}$. The residual division of these filaments in the absence of replication should also increase as a function of the time spent at $42{ }^{\circ} \mathrm{C}$. The results in Fig. 4 show that this was the case.

These results do not support the possibility that the SOS-associated inhibition of division is responsible for the lack of residual division in the presence of nalidixic acid in filaments when returned to $30^{\circ} \mathrm{C}$. We would have to admit in such a case that the $f$ ts $A 2$ allele renders the cells resistant to SOS-mediated cell division inhibition, and therefore that septa on which the $f t s A$ gene product has interacted (Tormo \& Vicente, 1984) are resistant to the action of SulA, the SOS division inhibitor (Gottesman et al., 1981; Huisman \& D'Ari, 1981; Mizusawa \& Gottesman, 
1983 ), or that $f t S A$ is a target of the SOS division inhibition pathway as is sulB (Lutkenhaus, 1983). Neither case would explain why strain D-3 filaments divide if replication is not inhibited immediately after the return to permissive conditions.

It has been suggested that inhibition of chromosome replication without alterations of other structural or physiological functions of the chromosome should not inhibit cell division (Helmstetter et al., 1979). Inhibition of DNA synthesis results in the induction of the SOS response (Little \& Mount, 1982), one of its effects being the inhibition of cell division. From the results obtained by several authors it seems that a pathway other than SOS, and independent of it, should coordinate cell division and replication. It has been reported (Inouye, 1971) that in the absence of replication (thymidine starvation or nalidixic acid treatment) rec $A$ strains divide and produce anucleated cells. The SOS response is inhibited in these strains as the RecA protein does not acquire the specific SOS protease function upon DNA damage or synthesis inhibition. After UV irradiation recA strains, as expected, do not undergo transient filamentation (Burton \& Holland, 1983). After chromosome replication inhibition, rec $A$ cells divide once, or at most twice, producing DNA-less cells and nucleated filaments. If the SOS pathway were the only control between replication and division, there should be continuous division of nucleated cells and no filamentation. It seems then that an additional mechanism to inhibit cell division after chromosome replication has to exist. Similar results are obtained if, instead of $\operatorname{rec} A$, lexA strains are used (Howe \& Mount, 1975, 1978). Since in these strains the lexA gene product is not cleaved by the RecA protease, the SOS response is blocked. Inhibition of DNA synthesis in lex $A$ strains leads to the formation of filaments, $85 \%$ of these being able to divide only once and $15 \%$ twice or more. Again, the existence of a SOS independent pathway coordinating replication and division arises.

A plausible explanation for the results obtained with strains D-3 and D-2 is that replication is a requirement for FtsA synthesis but not for its action. If the FtsA action requires replication, cell division in the absence of replication should be prevented in strain D-2 filaments. Conversely, if the action of FtsA does not require replication, a residual division of strain D-2 filaments at $30^{\circ} \mathrm{C}$ in the absence of DNA synthesis should be observed. As this latter alternative is found experimentally (Figs 3 and 4) it seems that the synthesis, but not the action, of the $f t s A$ gene product requires replication.

The existence of a protein that may affect cell division but is not dependent on the SOS response has been detected in lon but not in lon ${ }^{+}$strains (Schoemaker et al., 1982). This finding accords with the existence of a division pathway, involving $f t s A$, that is not directly regulated by the SOS inducible genes, in contrast to the situation for sulB (equivalent to $f t s Z$ ), the neighbour gene of $f t s A$ (Lutkenhaus, 1983). We have shown that the $f t s A$ gene product participates in the formation of the septum (Tormo \& Vicente, 1984); it would not be surprising to find that septation proteins are responsible for some of the regulatory functions needed by the cell to coordinate replication and cell division, so as to grow and divide in a balanced fashion. The relationship between the SOS-mediated inhibition of division and the action of $f$ ts $A$ remains to be elucidated.

We thank E. Martínez-Salas and M. Aldea for their comments. This research was financed by grant $3163 / 79$ to M. V. and partly by a grant to J. L. Cánovas both from Comisión Asesora de Investigación Cientifica y Técnica. A. T. was on leave from Colegio Universitario Integrado, Universidad Complutense de Madrid.

\section{REFERENCES}

Barbe, J., Vericat, J. A. \& Guerrero, R. (1983). Discriminated induction of SOS functions in Escherichia coli by alkylating agents. Journal of General Microbiology 129, 2079-2089.

Burton, P. \& Holland, I. B. (1983). Two pathways of division inhibition in UV-irradiated $E$. coli. Molecular and General Genetics 190, 128-132.

Clark, D. J. (1968). Regulation of deoxyribonucleic acid replication and cell division in Escherichia coli B/r. Journal of Bacteriology 96, 1214-1224.

Clowes, R. C. \& Hayes, W. (1968). Experiments in
Microbial Genetics. Oxford: Blackwell Scientific Publications.

Donachie, W. D., Begg, K. J. \& Vicente, M. (1976). Cell length, cell growth and cell division. Nature, London 264, 328-333.

Donachie, W. D., Begg, K. J., Lutkenhaus, J. F., Salmond, G. P. C., Martinez-Salas, E. \& Vicente, M. (1979). Role of the $f t s A$ gene product in control of Escherichia coli cell division. Journal of Bacteriology 140, 388-394.

Gottesman, S., Halpern, E. \& Trisler, P. (1981). 
Role of sulA and sulB in filamentation by lon mutants of Escherichia coli K-12. Journal of Bacteriology 148, 265-273.

Helmstetter, C. E. \& Pierucci, O. (1968). Cell division during inhibition of DNA synthesis in Escherichia coli. Journal of Bacteriology 95, 16271633.

Helmstetter, C. E., Pierucci, O., Weinberger, M., Holmes, M. \& TANG, M. (1979). Control of cell division in Escherichia coli. In The Bacteria, a Treatise on Structure and Function, vol. VII, pp. 517579. Edited by J. R. Sokatch \& L. N. Ornston. New York: Academic Press.

Howe, W. E. \& Mount, D. W. (1975). Production of cells without deoxyribonucleic acid during thymidine starvation of lexA cultures of Escherichia coli $\mathrm{K}$ 12. Journal of Bacteriology 124, 1113-1121.

Howe, W. E. \& MounT, D. W. (1978). Analysis of cell division in single clones of the Escherichia coli $\mathrm{K}-12$ lexA mutant. Journal of Bacteriology 133, 1278-1281.

Huisman, O. \& D'ARI, R. (1981). An inducible DNA replication-cell division coupling mechanism in $E$. coli. Nature, London 290, 797-799.

INOUYE, M. (1971). Pleiotropic effect of the rec $A$ gene of Escherichia coli: uncoupling of cell division from deoxyribonucleic acid replication. Journal of Bacteriology 106, 539-542.

Jones, N. C. \& DonaChIE, W. D. (1973). Chromosome replication, transcription and control of cell division in Escherichia coli. Nature New Biology 243, 100-103.
Little, J. W. \& Mount, D. W. (1982). The SOS regulatory system of Escherichia coli. Cell 29, 11-22.

LUTKENHAUS, J. F. (1983). Coupling of DNA replication and cell division: $s u l B$ is an allele of $f t s Z$. Journal of Bacteriology 154, 1339-1346.

Lutkenhaus, J. F., Moore, B. A., Masters, M. \& DonACHIE, W. D. (1979). Individual proteins are synthesized continuously throughout the Escherichia coli cell cycle. Journal of Bacteriology 138, 352-360.

Mizusawa, S. \& Gottesman, S. (1983). Protein degradation in Escherichia coli: the lon gene controls the stability of sulA protein. Proceedings of the National Academy of Sciences of the United States of America 80, 358-362.

Schoemaker, J. M., Henderson, G. W. \& Markovitz, A. (1982). Escherichia coli polypeptide controlled by the lon (capR) ATP hydrolysis dependent protease and possibly involved in cell division. Journal of Bacteriology 152, 919-923.

TORMo, A. \& VICENTE, M. (1984). The $f t s A$ gene product participates in formation of the Escherichia coli septum structure. Journal of Bacteriology 157, 779-784.

Tormo, A., Martinez-Salas, E. \& Vicente, M. (1980). Involvement of the $f$ ts $A$ gene product in late stages of the Escherichia coli cell cycle. Journal of Bacteriology 141, 806-813.

WITKIN, E. M. (1976). Ultraviolet mutagenesis and inducible deoxyribonucleic acid repair in Escherichia coli. Bacteriological Reviews 40, 869-907. 